\title{
IODP Expedition 328: Early Results of Cascadia Subduction Zone ACORK Observatory
}

\author{
by Earl Davis, Martin Heesemann, and the IODP Expedition 328 \\ Scientists and Engineers
}

\begin{abstract}
Integrated Ocean Drilling Program (IODP) Expedition 328 was devoted to the installation of an "Advanced CORK" (Circulation Obviation Retrofit Kit) in the Cascadia subduction zone accretionary prism to observe the physical state and properties of the formation as they are influenced by long-term and episodic deformation and by gas hydrate accumulation. Pressures are monitored at four levels on the outside of a standard 103/4-inch casing string, two above and two below the base of the gas-hydrate stability zone at $230 \mathrm{mbsf}$ ( $\mathrm{m}$ below seafloor). The casing was sealed at the bottom, leaving the inside open down to $302 \mathrm{mbsf}$ for installation of a tilt meter, seismometer, and thermistor cable (scheduled for 2013). The initial data, recovered in July 2011 , document an initially smooth recovery from the drilling perturbation followed by what may be a sequence of hole-collapse events. Pressure at the deepest screen is roughly $40 \mathrm{kPa}$ above hydrostatic; higher pressures $(80 \mathrm{kPa})$
\end{abstract}

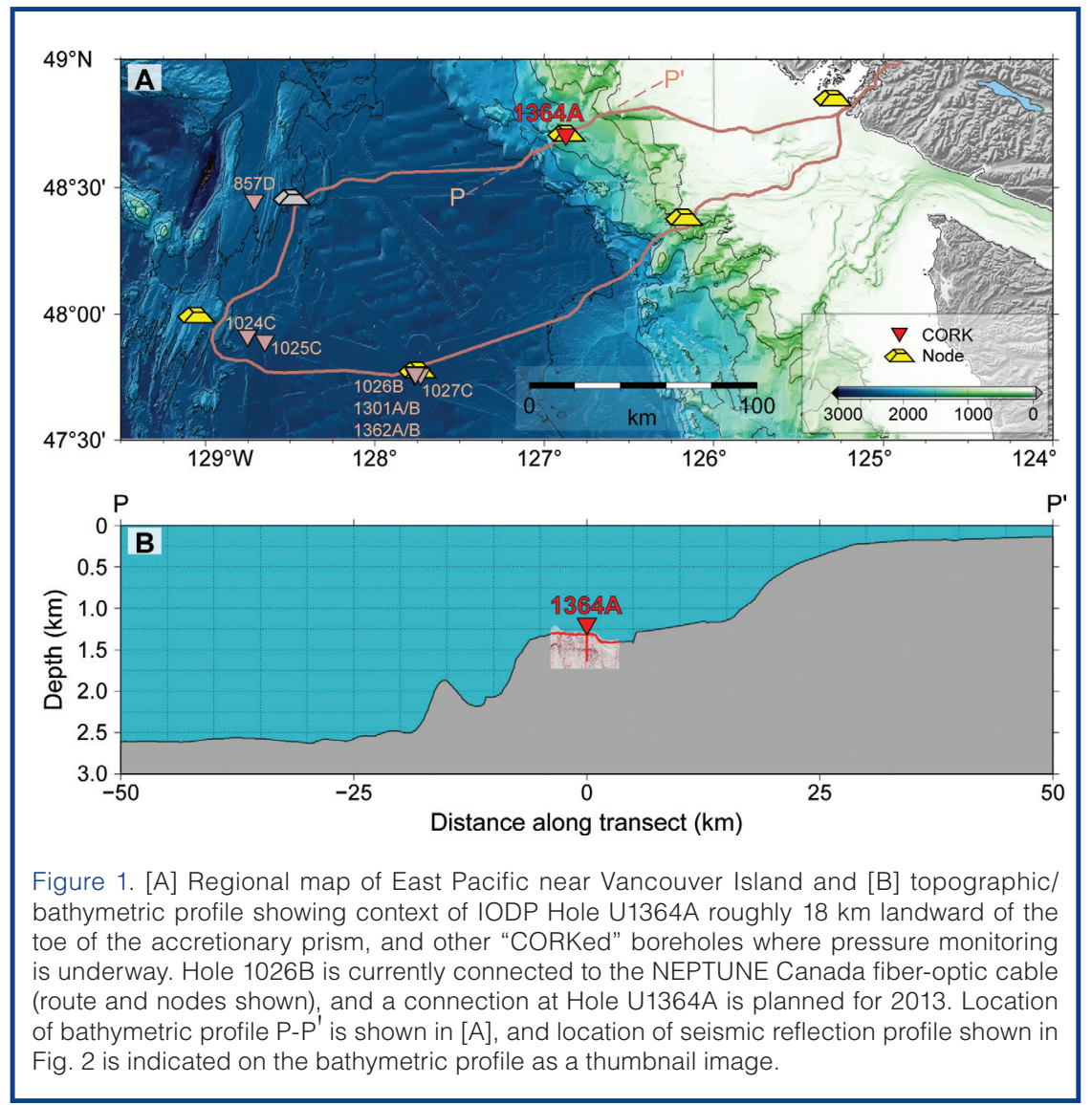

are observed at the two screens close to the level of hydrate stability. Tidal variations at the deepest screen are in phase with ocean tides, and define a loading efficiency of 0.6 , which is reasonable in light of the consolidation state of the for-mation (porosity 0.5). Tidal signals near the level of gas hydrate stability display large phase lags, probably as a consequence of hydraulic diffusion stimulated by the large contrast in interstitial fluid compressibility at the gas-hydrate boundary. The degree of isolation among the screens, the anticipated good coupling, and the estimated strain-to-pressure conversion efficiency $\left(\sim 5 \mathrm{kPa} \mu\right.$ strain $\left.^{-1}\right)$ indicate that this installation will serve well to host a variety of hydrologic, seismic, and geodynamic experiments.

\section{Introduction}

Operations carried out during IODP Expedition 328 were devoted to the installation of a borehole hydrologic observatory near ODP Site 889, the location chosen for one of the first CORK observatories during ODP Leg 146 in 1992

(Westbrook et al., 1994; Davis et al., 1995). In that early attempt, the relatively unstable sediments of the formation intruded rapidly through the perforations and bottom of an open-ended casing liner and prevented proper sealing of the hole. The new installation utilized the ACORK design, developed initially for installations at the Nankai subduction zone during ODP Leg 196 to permit pressure monitoring at multiple formation levels on the outside of a $103 / 4$-inch casing string. The casing is sealed at the bottom, leaving the inside fully isolated from the formation but available for future installations of additional monitoring instruments.

A broad range of objectives will be addressed with monitoring over the decades to come, some the same as those to have been addressed by the original CORK installation in Hole 889C including documenting the average state of pressure and constraining the vertical component of fluid flow from the consolidating sediments in the frontal part of the Cascadia accretionary prism, and investigating the mode of formation of gas hydrates. Other objectives have been added 


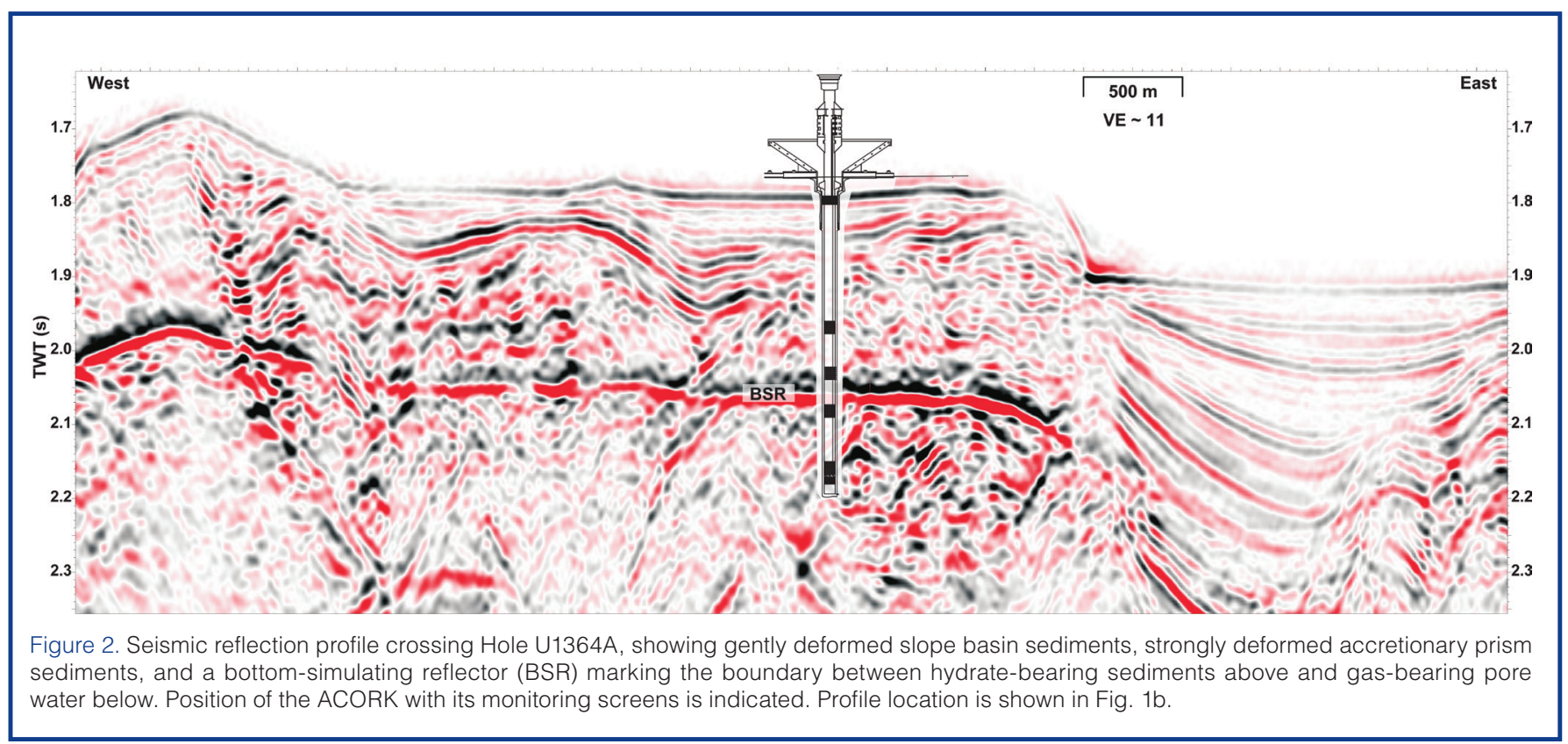

subsequently as a result of the multiple discrete monitoring levels provided by the ACORK configuration, advances in measurement resolution and sampling frequency, and knowledge gained from other monitoring experiments. These include determining the influence of gas hydrates and free gas on the mechanical properties of their host lithology, the response of the formation to seismic ground motion, and the magnitude of strain at the site caused by any episodic seismic or aseismic slip in this subduction setting. Instrumentation deployed at the time of drilling includes autonomously recording seafloor and formation pressure and seafloor temperature sensors. Sensors planned for deployment inside the sealed casing at a later date will measure temperature, tilt, and seismic ground motion. In 2013, all instruments will be connected to the NEPTUNE Canada fiber-optic cable for power and real-time communications. This will provide a greater sampling rate, time accuracy, and monitoring lifetime than what is possible with autonomous operations using battery power and local data storage.

\section{Geologic Setting}

As shown in Fig. 1, IODP Site U1364 lies $18 \mathrm{~km}$ landward of the toe of the Cascadia subduction zone accretionary prism, where much of the thick section of turbidite and hemipelagic sediments deposited on the eastern flank of the Juan de Fuca Ridge are scraped off the underthrusting oceanic crust (Davis and Hyndman, 1989; Hyndman et al., 1990; Westbrook et al., 1994). Convergence of the Juan de Fuca oceanic plate relative to the North American continental plate occurs in a direction roughly normal to the continental margin and at a rate of roughly $42 \mathrm{~mm} \mathrm{y}^{-1}$ (DeMets et al., 1990). A topographic trench at this subduction zone is absent as a consequence of the extremely high rate of glacial sediment supply from the continent during the Pleistocene. The majority of the supply has been impounded by the elevated igneous crustal topography of the Juan de Fuca Ridge. At the accretionary prism toe (also referred to as the deformation front, where the seawardmost thrust fault of the accretionary complex intersects the seafloor), the sediments that bury the eastern Juan de Fuca Ridge flank are approximately $2.7 \mathrm{~km}$ thick. At Site U1364 the accreted sedimentary section is nearly doubled to a thickness of approximately $5 \mathrm{~km}$ (Yuan et al., 1994). With tectonic thickening and compaction, pore fluids are expelled, and gas_-primarily biogenic methaneis transported upward to contribute to the formation of gas hydrates in the upper few hundred meters of the sediment section (Davis et al., 1990; Hyndman and Davis, 1992; Haacke et al., 2007; Riedel et al., 2010).

The location for Site U1364 was chosen for the same reasons as Site 889. It lies at a position landward of the prism toe where the fluid expulsion rate, estimated on the basis of the rates of compaction and vertical growth of the prism, reaches a cross-margin maximum, and where a clearly developed bottom simulating reflector marks the base of the gas hydrate stability field (Davis et al., 1990). Other holes drilled earlier during ODP Leg 146 and IODP Expedition 311 (Westbrook et al., 1994; Riedel et al., 2010) have documented the nature of the incoming undeformed sediments, the compaction history during accretion, the details of the lithology, and the distribution and composition of gas hydrates across the area. This information, along with detailed site survey studies (Scherwath et al., 2006; Riedel et al., 2010), provided an excellent basis for planning the depth, location, and other details of the ACORK installation at Site U1364 and established a valuable context for ACORK observations.

\section{Instrumentation}

Hole U1364A was drilled to a total depth of $336 \mathrm{mbsf}$ through roughly $90 \mathrm{~m}$ of gently deformed slope-basin deposits and underlying sediments of the accretionary prism that 


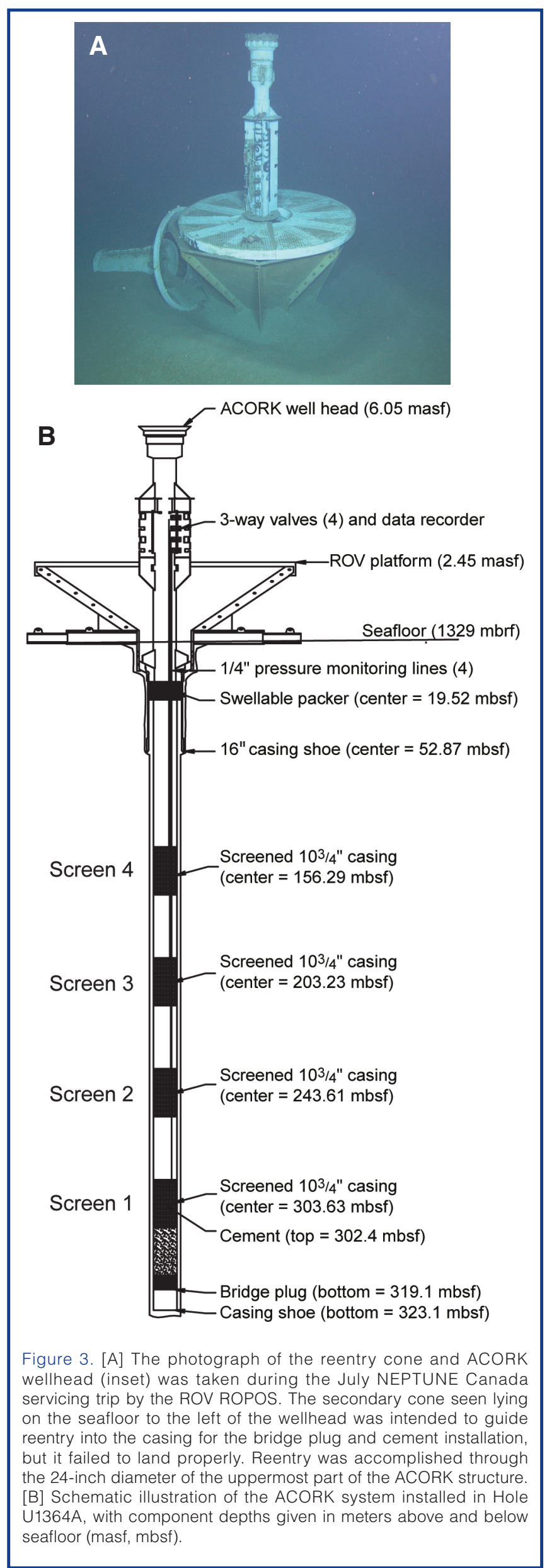

are folded and faulted on a scale too small to be resolved in seismic reflection profiles (Fig. 2). The configuration of the ACORK, constructed around solid 103/4-inch casing and installed immediately after drilling, is shown schematically in Fig. 3b. Formation fluid pressures are transmitted to sensors at the wellhead (inset Fig. 3a) via 2.03-m-long circumferential sand-packed filter screens and 3-mm-diameter (1/8-inch i.d.) stainless steel hydraulic tubing mounted on the outside of the casing. The solid casing is open at the seafloor but sealed at the bottom with a bridge plug backed with cement, leaving the interior open to a depth of $302 \mathrm{mbsf}$ for instruments requiring thermal or mechanical-but not direct-contact with the formation. Screens (numbered $\mathrm{S} 1$ to S4 from bottom to top) are positioned at depths of $304 \mathrm{mbsf}, 244 \mathrm{mbsf}, 203 \mathrm{mbsf}$, and $156 \mathrm{mbsf}$. The middle two pressure monitoring screens of the ACORK system (S2, S3) were positioned $14 \mathrm{~m}$ below and $27 \mathrm{~m}$ above the limit of gas hydrate stability at $230 \mathrm{mbsf}$ to observe the effects of free gas and gas hydrate in the sediment matrix, and diffusive signals originating at the hydrate-gas boundary. The lowermost and uppermost screens (S1, S4) were placed $74 \mathrm{~m}$ below and above the boundary, a distance that was anticipated to be sufficient to avoid hydrologic complications originating at the boundary.

Instrumentation installed with the ACORK included five pressure sensors, four plumbed to be switchable between the formation screens and the ocean and the fifth plumbed permanently to the ocean, and a platinum thermometer sensing ocean temperature at the wellhead. Frequency output of the pressure sensors is measured with a low-power, high-precision $(1 \mathrm{ppb})$ period counter. Data are stored in flash memory, and passed through to a communications port (i.e., to fiber-optic cable when connected). Under battery power, data are logged at one-minute intervals (programmable); under cable power, data are recorded at one sample per second. An on-board voltage detector automatically switches between the two modes. Calibration among sensors was done at the seafloor during deployment before the screens entered the hole, and will be done periodically to check for sensor drift though the use of three-way valves that can close the formation lines and connect the formation sensors to the open ocean. Temperature at the wellhead is determined with a highly stable platinum thermometer inside the instrument pressure case, and with one of the pressure sensors that contains a temperature-sensitive quartz oscillator. Further details about the instrumentation, the ACORK hardware, and the geologic setting are provided in Davis et al. (2010).

\section{Early Data}

Connection of the instrumentation at Hole U1364A to the NEPTUNE Canada fiber-optic cable system is planned for 2013; in the meantime, data are being logged autonomously using on-board battery power. The site was first visited with the remotely operated vehicle ROPOS in 2011 July (dive 
R1430) as part of a NEPTUNE Canada service cruise. The early portion of the downloaded record (with the full length of the ACORK assembly in the water column) is shown in Fig. 4. The 1-minute-interval data record of the deployment shows a highly aliased view of the effects of heave resulting from both depth variations and acceleration of the water in the hydraulic tubing. The latter produced sys-tematically increasing amplitudes from the uppermost to lowermost screens. Average values of the pressure difference between the various screens and the seafloor (SF) allow correction for inaccuracy of the sensor calibrations (see Fig. 4).

Pressures recorded during the ACORK entry and installation (Fig. 5) show growing offsets and modest overpressures as the screens enter the hole. Peak pressures exceeded those that would be produced by the drilling mud used to prevent premature hole collapse $\left(\rho=10.4 \mathrm{lb} \mathrm{gal}^{-1}=1200 \mathrm{~kg} \mathrm{~m}^{-3}\right)$ by $50 \%-80 \%$. This may be a result of charging of the formation by water and mud pumped during drilling and casing installation. Pressure variations present during the early installation phase abated when the drill string was disconnected, and briefly returned after reentry for the bridge plug and cement installations. The drop in pressure at the time of cementing at screen S2, and to a lesser extent at screen S3, may have been caused by the temporary cooling effects of circulating drill mud during that operation, possibly with free gas being driven into solution.

After completion of the installation, pressures began a relatively smooth decay for roughly one week, then showed multiple, generally sympathetic perturbations (tentatively inferred to be the consequence of hole collapse) before entering a period of relative stability (Fig. 6). Hydrologic isolation between adjacent screens and between screens and the seafloor is apparent from the attenuation of the tidal load at the seafloor. Ratios of the formation to seafloor signal amplitudes, referred to as the tidal loading efficiency, were roughly $0.7,0.5,0.6$, and 0.9 at screens $\mathrm{S} 1-\mathrm{S} 4$, respectively, early in the recording period (Fig. 7), and declined to roughly $0.6,0.3,0.4$, and 0.7 by the end of the recording period. The value for screen S1 at $304 \mathrm{mbsf}$ is comparable to values observed elsewhere in sediments of equivalent porosity ( 50\%; Davis and Villinger, 2006; Davis et al., 2009)

The greater degree of attenuation and phase lag of the signal at screen S2 relative to the loading at the seafloor is indicative of free gas in the sediments below the level of gas hydrate stability. Attenuated amplitude would result from the high compressibility of gas-bearing water in the sediment pore volume, and a change of phase would result from $0.1 \mathrm{~m}$..

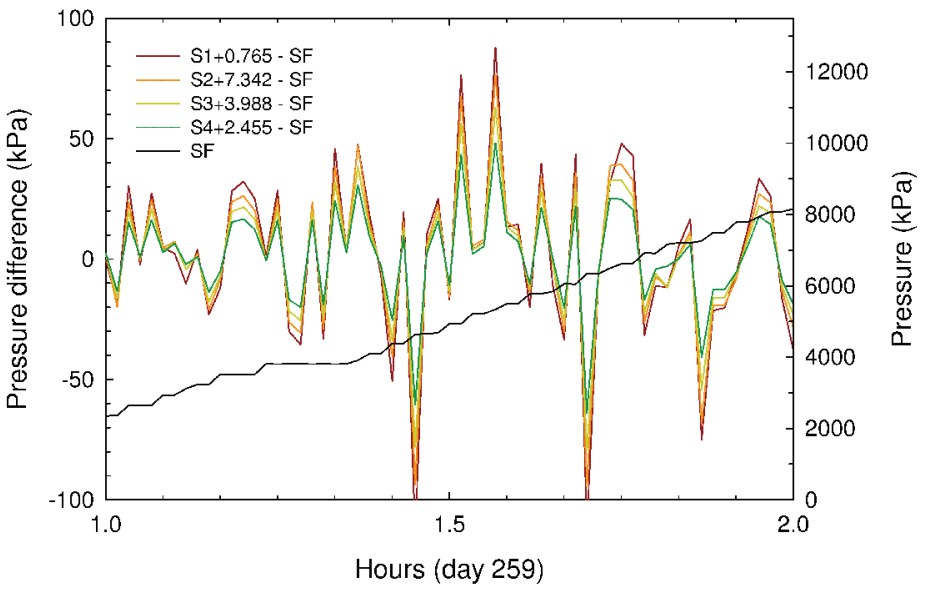

Figure 4. Pressure variations measured during the decent of the ACORK system. Screen pressures are shown relative to the seafloor sensor pressure (scale on left). Offsets given in legend are applied in this and other figures. Absolute pressure is shown for the seafloor sensor (scale on right). Units used for differential and absolute pressure in this and other plots are $\mathrm{kPa}$, equivalent to a seawater head of

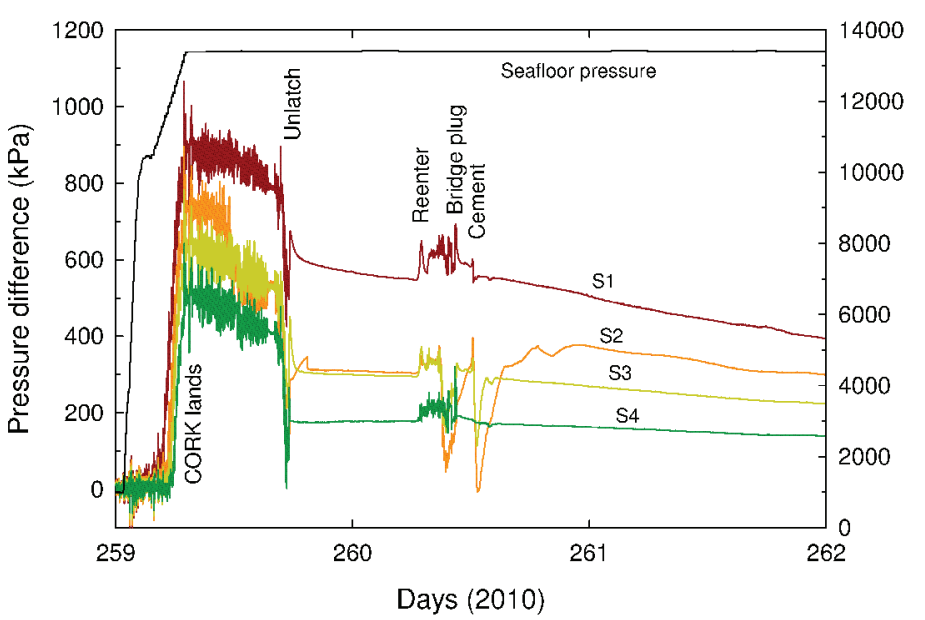

Figure 5. Record of pressure variations (screen pressures relative to seafloor, seafloor pressure absolute) measured during the Site U1364 ACORK installation, annotated with operational events.

a diffusive signal generated by the large contrast in fluid and possibly matrix compressibilities at the gas/gas-hydrate boundary (Wang and Davis, 1996; Wang et al., 1998). Lack of a phase difference at screens S1 and S4 relative to the seafloor loading suggests that they are sufficiently far from the gas/gas-hydrate boundary for diffusive effects to be absent. The scale over which this is true depends on the period of the loading signal and the hydraulic diffusivity (permeability and storage compressibility) of the formation. A full analysis of the nature of loading will be done once high-sampling-rate data are available via the connection to the NEPTUNE Canada cable system, and an examination over a broad frequency band (e.g., ranging from microseismic to seasonal) is possible. 
The full history (Fig. 8a) reveals complexities that are currently not understood. During the first eighty days of the recording period, pressures varied over days to weeks. Variations are largest at the uppermost screen (S4) and smallest at the lowermost (S1), and variations at the lower three screens mirror those at the uppermost. Thermal perturbations that might be caused by vertical flow in the annulus outside the casing (warm water transported up, cool solids down) could produce this difference (i.e., with sediment settling into the lower part of the hole causing cooling and a temporary decline in pressure arising from thermal contraction of the fluid in the screens and hydraulic tubing, and expelled water warming the uppermost interval), although any heating above the uppermost screen would

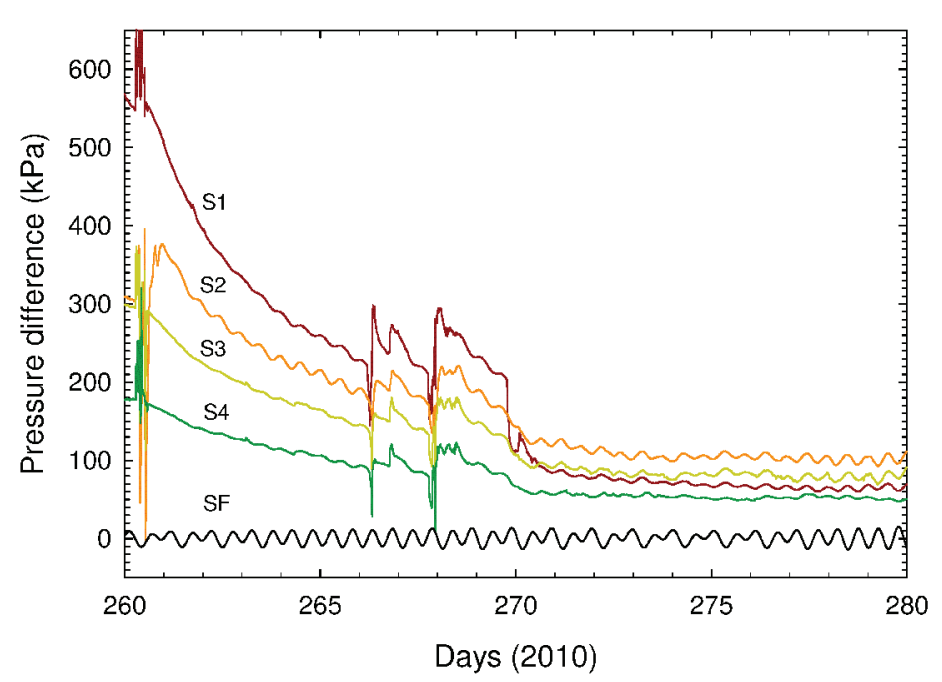

Figure 6. Three-week record of the decay of screen pressures (relative to seafloor) following the ACORK installation at Hole U1364A. Absolute seafloor pressure is shown with the same scaling as the relative pressures at screens but with the mean seafloor pressure removed.

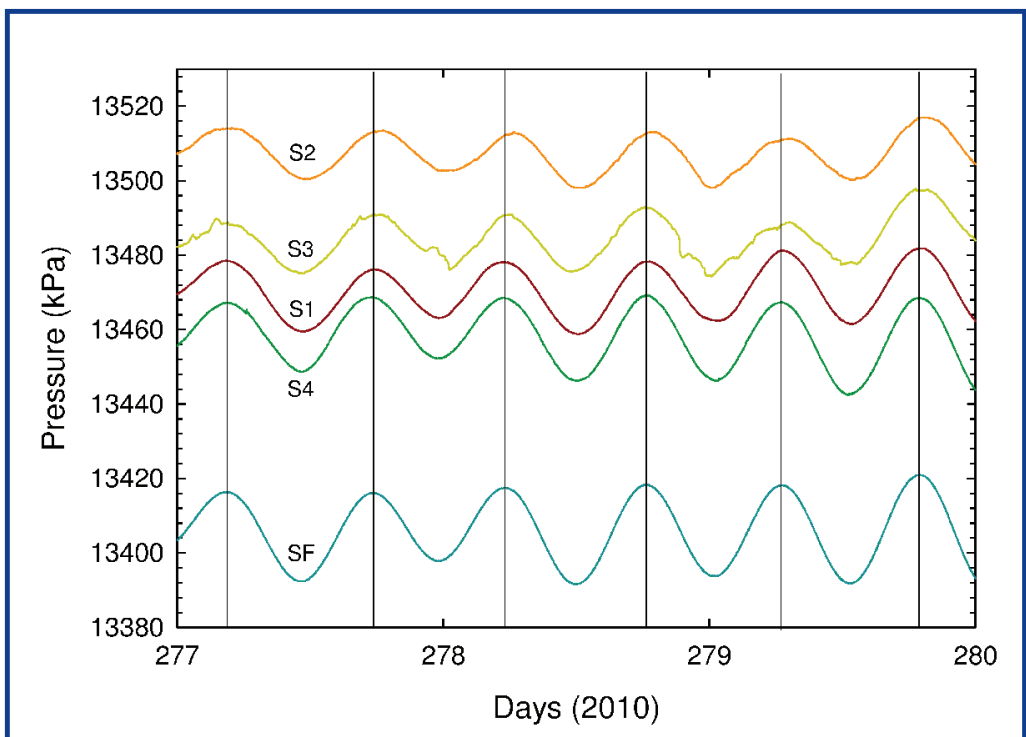

Figure 7. Three-day record of absolute seafloor and screen pressures, showing the dominant tidal component of variation. Differences in amplitudes and phases of pressure variations in the formation relative to pressure at the seafloor are discussed in the text. Lines at times of seafloor tidal peaks highlight the large phase lag of the signal at screen S2. affect all hydraulic lines equally. Fortunately, towards the end of the initial 160-day recording period, pressures settled to levels similar to those prior to the first major perturbations, although an elevated level of "noise" persists, most notably at the upper two screens. Highest average pressures are present at the two screens immediately above and below the base of the gas-hydrate stability field, and lowest at the uppermost screen.

On 21 February (day 417 on plot), the seafloor pressure sensor suffered a failure possibly caused by crevice corrosion penetrating beneath the O-ring seal of its electrical connector. Excess current to the seafloor sensor was detected by the instrument, current was limited, and the problem was flagged in the stored data, but after roughly thirty minutes the leakage produced a short circuit, leaving all channels dysfunctional. On 24 July (ROPOS dive R1452) the cable to the faulty sensor was cut, which restored the system functionality. A brief interval of on-site logging showed the remaining sensors to be fully opera-tional and the formation pressure state to be similar to that seen in February.

Temperatures were measured throughout the history of the recording period with the temperature-dependent oscillator in the seafloor pressure sensor and with the platinum thermometer (Fig. 8b). Absolute accuracy is limited to a few tenths of a degree Celsius; calibration will be improved by comparing values to an accurately calibrated conductivity-temperature-depth (CTD) sensor during the next ROPOS visit. Precision of both sensors is much better than the accuracy; variations in the two records follow one another within a few milliKelvin. Small differences are primarily the consequence of the thermal time constant of the pressure sensor being longer than that of the platinum thermometer. Temporal variations are seen from diurnal to seasonal periods.

\section{Summary and Discussion}

Data from the first five months of seafloor and formation pressure recording at Hole U1364A at the toe of the Cascadia subduction zone accretionary prism have demonstrated that the IODP ACORK multi-level hydrologic monitoring system will provide well isolated hydrologic observations in the sedimentary formation via hole closure around external casing screens at relatively shallow levels ( $300 \mathrm{mbsf})$. However, persistent noise, particularly at the uppermost screen (156 mbsf), suggests variable leakage in the annulus outside the casing. Borehole temperature monitoring, planned with other instrument installations inside the casing in 2013, will provide a sensitive test for any long-term or episodic vertical flow. 
Formation pressures measured at the monitoring screens range from $40 \mathrm{kPa}$ to $80 \mathrm{kPa}$ above hydrostatic. These are significant but not high, i.e., a small fraction of the lithostatic potential at the deepest screen of roughly $2 \mathrm{MPa}$. High pressures are not expected at this relatively shallow level in the prism, given the relatively high formation permeability and the long time that has elapsed ( 300 years) since the last large subduction earthquake when large contractional strain may have been produced in the outermost part of the prism. Highest pressures are observed at the screens immediately above and below the level of gas hydrate stability (marked both at this location and regionally by a clear bottom simulating seismic reflector). This may be a consequence of ongoing gas production.

While information about dynamic response to seafloor loading over a broad range of frequencies will not be available until the instrumentation is connected to the NEPTUNE Canada power and communications cable, variations in the amplitude and phase of loading at tidal frequencies provide some preliminary insights. There is a general decline in the tidal amplitude at all screens with time, suggesting a progressive increase in the degree of closure of the formation around the casing with time. At the deepest screen, formation pressure variations are in phase with the seafloor load throughout the record, demonstrating that there is no significant hydrologic diffusion or leakage at this level. The tidal loading efficiency (formation/seafloor $=0.6$ late in the record) is consistent with observations in other sedimentary sections with similar porosity, and suggests that the formation is sufficiently rigid for volumetric strain to be detected with pressure (i.e., with a conversion efficiency of roughly $5 \mathrm{kPa} \mu$ strain $^{-1}$; Davis et al., 2009).

The tidal signal at the screen just below the hydrate stability boundary (S2) is anomalously low in amplitude (formation/seafloor $=\sim 0.3$ late in the record) and lags the seafloor load by roughly two hours. The low amplitude is probably the consequence of the high compressibility of interstitial free gas, and the large phase lag is likely the consequence of a diffusive signal propagating from the gas/gas-hydrate boundary, where there may be a sharp contrast in both matrix and interstitial fluid compressibilities.

\section{Acknowledgments}

Installation of the CORK observatory at Hole U1364A seemed like a routine operation as a result of the skilled help of IODP shipboard technical, operations, and engineering
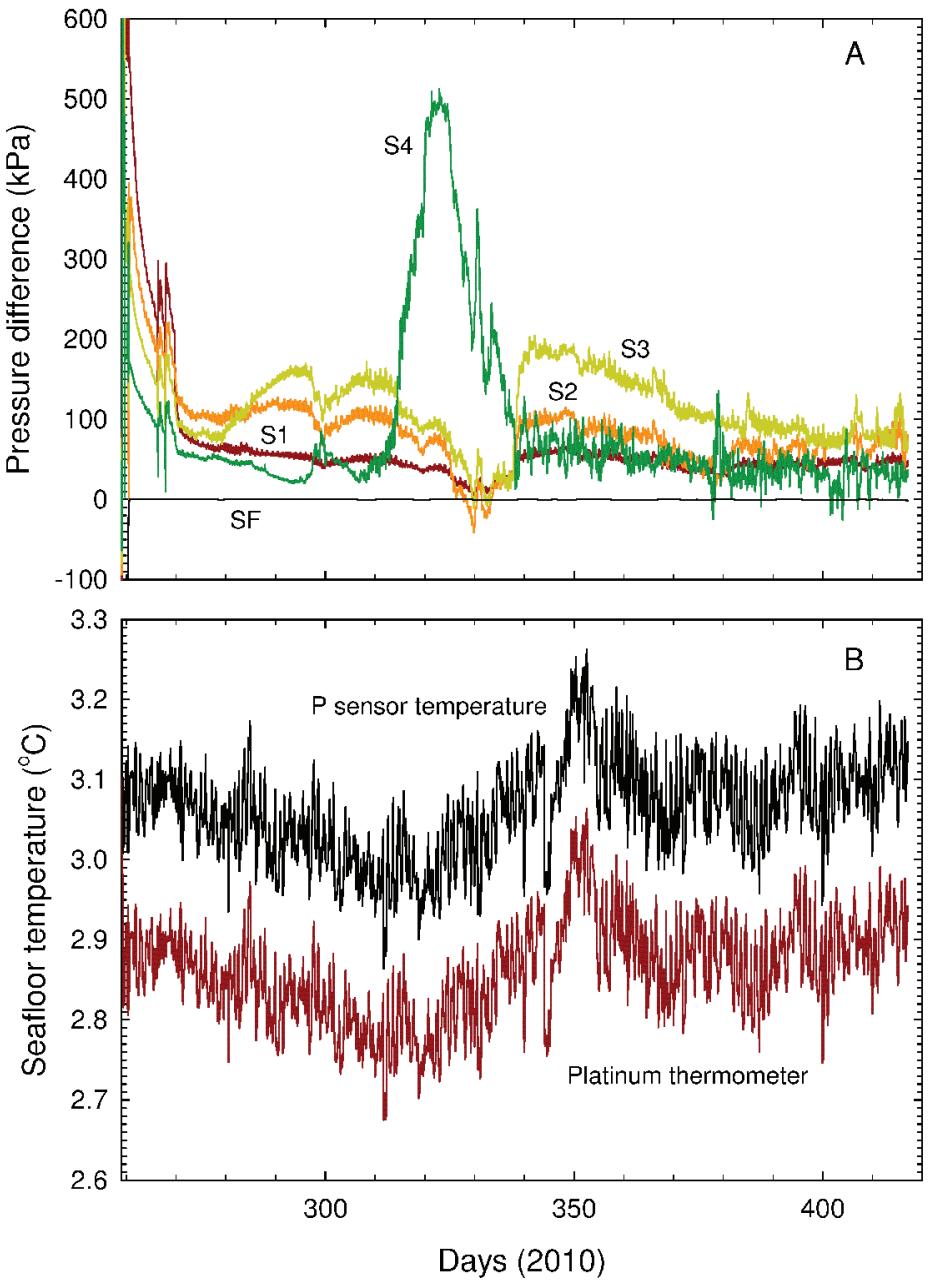

Figure 8. Full history of $[A]$ seafloor (tides filtered) and relative formation pressures and $[B]$ seafloor temperature observed prior to failure of the seafloor pressure sensor on 21 February 2011 (day 417). Scaling convention for pressures is the same as in Figs. 4-6. Temperatures (offset for plotting clarity; absolute values to be calibrated during the next ROPOS visit) are measured inside the main strument pressure case with a platinum thermometer, and inside the seafloor pressure sensor with a quartz oscillator.

personnel and the crew on D/V JOIDES Resolution, led by Mitch Malone, Bill Rhinehart, and Bob Aduddell. Michael Riedel provided invaluable information about local seismic and lithologic structure. Zest was added to the short cruise by the energetic leaders and participants of the IODP School of Rock. Data downloading operations and remediation of the problem created by the seafloor pressure sensor failure were carried out by the crew of the remotely operated vehicle ROPOS, led by Keith Shepherd and assisted by Martin Scherwath and Reece Hasanen of NEPTUNE Canada. Support for the design and construction of the wellhead instrumentation prior to the expedition was provided by Robert Macdonald, Robert Meldrum, James Guenther, John Bennest, Jonathan Schmidt, and David Miles. Pressure sensors, sensor frequency counters, and the NEPTUNEcompatible data logger were provided by Paroscientific Inc., Bennest Enterprises Ltd., and Minerva Technologies Ltd., respectively. 


\section{The IODP Expedition 328 Scientists and School of Rock Educators}

E. Davis, M. Malone, M. Heesemann, M. Riedel, D. Divins, J. Collins, K. Ludwig, S. Hovan, M. Reagan, and S. Slough

\section{References}

Davis, E., Becker, K., Wang, K., and Kinoshita, M., 2009. Co-seismic and post-seismic pore-fluid pressure changes in the Philippine Sea plate and Nankai decollement in response to a seismogenic strain event off Kii Peninsula, Japan. Earth Planets Space, 61:649-657.

Davis, E.E., and Hyndman, R.D., 1989. Accretion and recent deformation of sediments along the Cascadia subduction zone. Geol. Soc. Am. Bull., 101:1465-1480. doi:10.1130/0016-7606 (1989)101\%3C1465:AARDOS\%3E2.3.CO;2

Davis, E.E., and Villinger, H., 2006. Transient formation fluid pressures and temperatures in the Costa Rica forearc prism and subducting oceanic basement: CORK monitoring at ODP sites 1253 and 1255. Earth Planet. Sci. Lett., 245:232-244.

Davis, E.E., Becker, K., Wang, K., and Carson, B., 1995. Long-term observations of pressure and temperature in Hole 892B, Cascadia accretionary prism. In Carson, B., Westbrook, G.K., Musgrave, R.J., and Suess, E. (Eds.), Proc. ODP, Sci. Results, 146 (Pt. 1): College Station, TX (Ocean Drilling Program), 299-311. doi:10.2973/odp.proc.sr.146-1.219.1995

Davis, E.E., Hyndman, R.D., and Villinger, H., 1990. Rates of fluid expulsion across the northern Cascadia accretionary prism: Constraints from new heat flow and multichannel seismic reflection data. J. Geophys. Res., 95:8869-8889. doi:10.1029/ JB095iB06p08869

Davis, E.E., Malone, M.J., and the Expedition 328 Scientists and Engineers, 2010. Integrated Ocean Drilling Program Expedition 328 Preliminary Report: Cascadia subduction zone ACORK observatory. IODP Prel. Rept., 328. doi:10.2204/iodp.pr.328.2010

DeMets, C., Gordon, R.G., Argus, D.F., and Stein, S., 1990. Current plate motions. Geophys. J. Int., 101:425-478. doi:10.1111/ j.1365-246X.1990.tb06579.x

Haacke, R.R., Westbrook, G.K., and Hyndman, R.D., 2007. Gas hydrate, fluid flow and free gas: Formation of the bottomsimulating reflector. Earth Planet. Sci. Lett., 261:407-420. doi:10.1016/j.epsl.2007.07.008

Hyndman, R.D., and Davis, E.E., 1992. A mechanism for the formation of methane hydrate and seafloor bottom-simulating reflectors by vertical fluid expulsion. J. Geophys. Res., 97:7025-7041. doi:10.1029/91JB03061

Hyndman, R.D., Yorath, C.J., Clowes, R.M., and Davis, E.E., 1990. The northern Cascadia subduction zone at Vancouver Island: Seismic structure and tectonic history. Can. J. Earth Sci., 27:313-319. doi:10.1139/e90-030

Riedel, M., Collett, T.S., and Malone, M., 2010. Expedition 311 synthesis: Scientific findings. In Riedel, M., Collett, T.S., Malone, M.J., and the Expedition 311 Scientists, Proc. IODP, 311: Washington, DC (Integrated Ocean Drilling Program
Management International, Inc.). doi:10.2204/iodp.proc. 311.213.2010

Scherwath, M., Riedel, M., Spence, G.D., and Hyndman, R.D., 2006. Data report: Seismic structure beneath the north Cascadia drilling transect of IODP Expedition 311. In Riedel, M., Collett, T.S., Malone, M.J., and the Expedition 311 Scientists, Proc. IODP, 311: Washington, DC (Integrated Ocean Drilling Program Management International, Inc.). doi:10.2204/iodp.proc.311.110.2006

Wang, K., and Davis, E.E., 1996. Theory for the propagation of tidally induced pore pressure variations in layered subseafloor formations. J. Geophys. Res., 101:11483-11495. doi:10.1029/ 96JB00641

Wang, K., Davis, E.E., and van der Kamp, G., 1998. Theory for the effects of free gas in subsea formations on tidal pore pressure variations and seafloor displacements. J. Geophys. Res., 103:12339-12354. doi:10.1029/98JB00952

Westbrook, G.K., Carson, B., Musgrave, R.J., et al., 1994. Proc. ODP, Init. Repts., 146 (Pt. 1): College Station, TX (Ocean Drilling Program). doi:10.2973/odp.proc.ir.146-1.1994

Yuan, T., Spence, G.D., and Hyndman, R.D., 1994. Seismic velocities and inferred porosities in the accretionary wedge sediments at the Cascadia margin.J. Geophys. Res., 99:4413-4427. doi:10.1029/93JB03203

\section{Authors}

Earl Davis, Pacific Geoscience Centre, Geological Survey of Canada, 9860 West Saanich Road, Sidney, BC V8L 4B2, Canada, e-mail: edavis@nrcan.gc.ca.

Martin Heesemann, NEPTUNE-Canada, University of Victoria, P.O. Box 1700 Stn CSC, Victoria, BC V8W 2Y2, Canada, e-mail: mheesema@uvic.ca.

and the IODP Expedition 328 Scientisits and Engineers 